\title{
Are phonological features of roots in syntax? Evidence from Guébie (Kru) Hannah Sande ${ }^{1}$ \\ LSA Annual Meeting, Portland, January 8-11, 2015
}

1. Introduction. Guébie (Kru, Niger-Congo) [Côte d'Ivoire] has a typologically remarkable agreement system where third person subject and object pronouns are phonologically determined by their antecedent nominals. This system questions the strict separation of phonological operations from the syntax and morphology (cf. Pullum and Zwicky 1988, 1986). In modeling this data, I argue that the phonological correspondence between pronouns and their antecedents is not a coincidence, but is due to a productive phonological process which requires identity between elided elements and their overt counterparts.

In my analysis, syntax, morphology work together to account for phonological agreement. I posit that the antecedent noun which determines the agreement is present in the syntax, but is elided at PF. An AGR-node is inserted on the pronoun D (cf. Halle and Marantz 1994), and features are copied to it from the Noun. The phonology, which applies cyclically by phase, requires phonological identity between those syntactic heads that share features. Ellipsis of the noun complement at PF is licensed by overt agreement (cf. Kester 1996); the noun can elide as long as the output string is as faithful as possible to its non-elided counterpart. This analysis provides insight into 1) the internal syntactic structure of pronoun-headed DPs, 2) the degree of segregation of morphosyntactic and phonological operations, and 3) by what means ellipsis occurs at PF.

2. The data: Pronoun/antecedent agreement in Guébie. There are ten vowels in Guébie. Tone is marked with numbers 1-4 where 4 is high. Subject and object pronouns have the form of a single vowel, $\mathrm{V}$, and can occur with or without an overt NP complement. The construction in (1a) is distinct from definiteness, topic, and focus, and is similar in function to We linguists in English.

\section{(1) Pronouns can occur with or without an overt NP complement}
a. [sukulu $\left.{ }^{1.1 .3} \mathrm{u}^{3}\right]$ 'it school'
b. [sukulu $\left.{ }^{1.1 .3} \mathrm{u}^{3}\right]$ 'it (the school)'

While the agreeing vowel for human nouns is always / $/$ /, the non-human nouns that take a given pronoun or modifier vowel do not form coherent semantic classes. Rather, the agreeing vowel is predictable by final vowel of the noun, including for loan and nonce words (cf. /sukulu/, 'school' in (1)). Rather than being determined by morphological gender, the third person pronoun is predictable by the phonological shape of its nominal antecedent (a singular or plural noun stem).

(2) Mapping of Guébie root-final vowels to pronoun vowels

\begin{tabular}{|c|c|c|c|c|c|c|c|}
\hline & Final vowel & & 3.SG pronoun vowel & \multicolumn{3}{|c|}{ Plural suffix } & 3.PL pronoun vowel \\
\hline a. & $\mathrm{i}, \mathrm{I}, \mathrm{e}, \mathrm{\varepsilon}$ & $\rightarrow$ & e & d. & $-\mathrm{i}$ & $\rightarrow$ & $\mathrm{i}$ \\
\hline b. & $\partial, \mathrm{a}$ & $\rightarrow$ & ə & e. & $-a$ & $\rightarrow$ & wa \\
\hline c. & $\mathrm{u}, \mho, \mathrm{o}, \mathrm{J}$ & $\rightarrow$ & $\mathrm{u}$ & & & & \\
\hline
\end{tabular}

The antecedent does not have to be in the same sentence, nor nearby within the discourse.

\footnotetext{
${ }^{1}$ Thanks to my advisors Larry Hyman and Peter Jenks, as well as Professor Sharon Inkelas, for their comments on various versions of this work. Thanks also to the audiences of a University of Minnesota linguistics colloquium and the 2014 QP Fest at UC Berkeley. A special thanks to my Guébie consultants Sylvain Bodji, Laureine, Emil Serikpa, Gnakouri, and Olivier Agodio. Author: Hannah Sande, UC Berkeley (sande570@berkeley.edu)
} 


\section{(3) Phonological agreement of pronouns with antecedents}

\begin{tabular}{|c|c|c|c|c|c|}
\hline & $\mathbf{S}$ & ic & Gl & ubj clitic & \\
\hline & $n$ & & 'I s & & 'It \\
\hline & 'af & & 'I s & $\underline{\mathbf{\theta}}^{3}$ & 'It \\
\hline c. to ${ }^{3}$ & 'battle' & $\mathrm{e}^{4} \mathrm{ni}^{-}{ }^{4} \underline{\mathbf{u}}^{2} \mathrm{ji}^{3}$ & 'I saw it (a battle)' & $\underline{\mathbf{u}}_{-}^{3} \mathrm{kad} \varepsilon^{3.2}$ & 'It (battle) is big.' \\
\hline
\end{tabular}

The same phonological correspondence holds between a noun and the final vowel of its adjectival modifiers. Word-internal ATR harmony influences the quality of the modifier's vowels.

(4) Noun-modifier phonological agreement
a. bite $^{2.3} \operatorname{lel}^{1.2} \underline{\mathrm{f}}^{1 . \underline{a}^{1.1}}$
b. $\quad \underline{\mathbf{u}}^{3}$ lelo $\underline{\mathbf{o}}^{1.2}$ jelo $\underline{\mathbf{o}}^{1.1}$
house new red sponge new red
'A new red house'
'A new red sponge'

Because this is a productive process that holds whether the agreement controlling noun is present in the utterance or not, that is, it is non-local, a purely phonological analysis cannot account for the Guébie data presented here.

A purely syntactic analysis to determine agreement would involve arbitrary lexical gender assignment. In this analysis the phonological predictability is coincidental. Some evidence against arbitrary assignment comes from plural markers. There are two distinct plural suffixes in Guébie, /-i/ and /-a/. They attach directly to the noun, and those nouns that select a given plural marker do not form a coherent semantic or phonological group. Thus, the plural suffix on the noun must be determined by arbitrarily assigned gender. We would not expect a second arbitrary assignment system, then, to determine the pronoun selection of a given nominal. Instead, the phonological features of the final vowel of a noun, singular or plural, determine the quality of the third person pronoun (3). The analysis in section 3 shows that when syntax, morphology, and phonology work together, we can account for the details of the analysis, predicting the phonological agreement, rather than being satisfied with it as arbitrary and coincidental.

3: The analysis. I argue for the following analysis of Guébie phonological agreement. Pronouns are D-heads requiring an NP complement (cf. Elbourne 2001). Morphological mechanisms ensure that an AGR-node is inserted on $\mathrm{D}$, and the $\mathrm{N}$ feature is copied to it from the noun. $\mathrm{DP}$ is a phase (Svenonius, 2004) and phonological operations, including ellipsis, apply post-syntactically at phase edges (Marvin 2002).

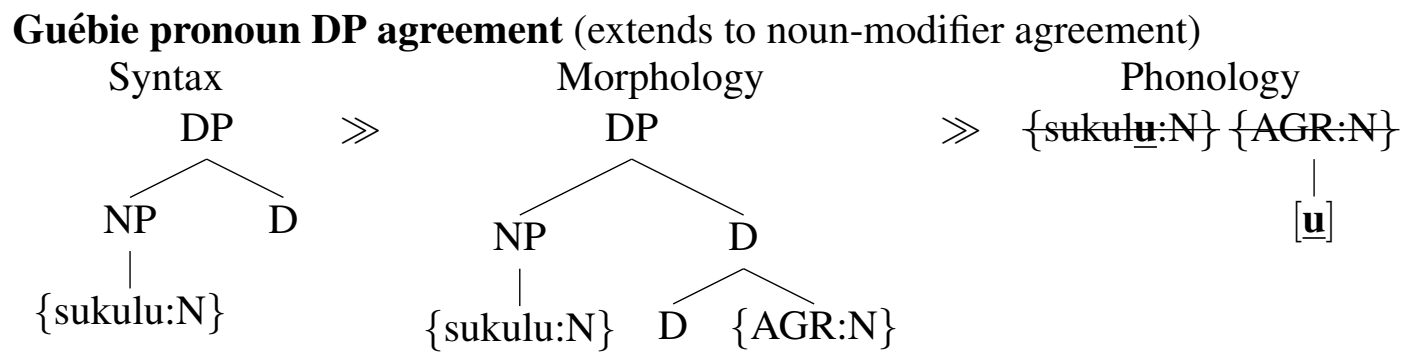

For the phonological agreement, I adapt an Agreement-by-Correspondence approach (Rose and Walker, 2004) combined with paradigm output-output faithfulness (Burzio, 1994; Benua, 1997; Kager et al., 1999). The phonology has access to morphological features within the phase to 
which it is applying. A highly ranked IDENT-OO(N) constraint ensures that any two heads that Agree in $\mathrm{N}$ features agree in final vowel quality. IDENT-IO ensures faithfulness to the input noun vowel. Positional faithfulness constraints ensure that only the final vowels agree, REALIZEMORPH penalizes unpronounced morphemes, and additional constraints are proposed to account for the reduced number of pronoun vowels compared to the full Guébie vowel inventory. These constraints accurately select the correct non-elided structures in Guébie: [sukulu u], [*sukulu e, *sukule e].

In order to account for those cases where the agreement-controlling noun is elided (1b), I propose a new model of ellipsis at PF. Syntactic consituents to be elided have a feature E (Merchant, 2001). The phonology has access to the $E$ feature of the noun, and the option of eliding the noun is available based on phonological constraint rankings. I propose the constraint FAITH-NOELIDE, which requires that an elided [Noun Pronoun] construction must be as faithful as possible to the alternative grammatical non-elided counterpart [Noun Pronoun]. This constraint assumes that the elided and non-elided versions of Noun-Pronoun constructions form a paradigm of possible output options, and it ensures that for example, the elided form [sukulu u] must be faithful in phonological features to the non-elided [sukulu u]. This analysis forces phonological agreement and provides the option of ellipsis at PF simultaneously via constraints.

(6)

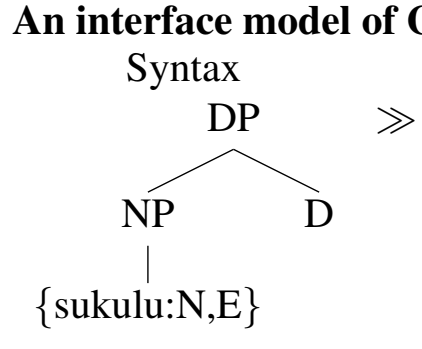

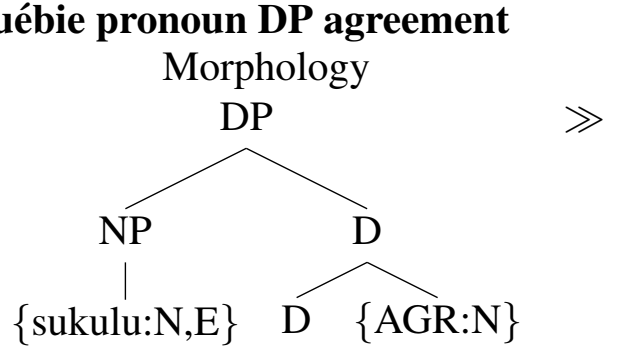

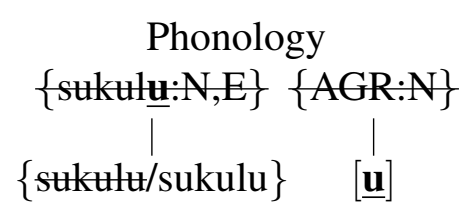

Here I claim that phonological agreement arises through phonological identity to non-elided forms via morphological agreement mechanisms, providing a formal account of ellipsis at the morphology-phonology interface. The proposed analysis for arriving at the correct output of thirdperson pronouns in Guébie easily extends to phonological agreement in Guébie adjectives, and we can modify it only slightly to account for Guébie first and second person pronouns.

Outside of Guébie, we find other Kru languages in which similar phonological agreement patterns hold (Bing, 1987; Marchese, 1979, 1988; Corbett, 1991). The analysis presented here can be extended to account for this similar process in other Kru languages. The analysis predicts that two heads may agree phonologically iff they are present in the same phase. Outside of Kru, phonologically determined agreement systems are rarely attested; however, there are a few such systems. These include Bainuk and Atlantic (Corbett, 1991; Dobrin, 1995). The phonological agreement in both of these languages can also be accounted for by the analysis presented here for Guébie.

4. Conclusion. Here I provide an initial description of the phonologically determined agreement system of Guébie (Kru, Niger-Congo). I present an interface analysis where agreement arises through phonological identity to output forms via morphological agreement mechanisms. This includes a formal account of ellipsis via constraints at PF.

The analysis presented here accounts for phonologically determined agreement systems crosslinguistically; however, I leave as a question for further research whether the proposed analysis could serve as a model of gender and noun class systems more generally. 
Crucially, I demonstrate that phonologically determined agreement systems can be modeled without requiring phonological features to be present in syntax. Thus, I conclude we can maintain that syntax is not sensitive to phonological features.

\section{References}

Benua, Laura. 1997. Transderivational identity. Doctoral Dissertation, University of Massachusetts, Amherst.

Bing, Janet. 1987. Phonologically conditioned agreement: Evidence from krahn. Current approaches to African linguistics 4 .

Burzio, Luigi. 1994. Principles of english stress. 72. Cambridge University Press.

Corbett, Greville. 1991. Gender. cambridge textbooks in linguistics. Cambridge: Cambridge .

Dobrin, Lise M. 1995. Theoretical consequences of literal alliterative concord. In The Proceedings of the 31st Regional Meeting of the Chicago Linguistic Society, volume 1, 127-142.

Elbourne, Paul. 2001. E-type anaphora as np-deletion. Natural Language Semantics 9:241-288.

Halle, Morris, and Alec Marantz. 1994. Some key features of distributed morphology. MIT working papers in linguistics 21:88.

Kager, René, Harry van der Hulst, and Wim Zonneveld. 1999. The prosody-morphology interface, volume 79. Cambridge University Press.

Kester, Ellen-Petra. 1996. Adjectival inflection and the licensing of empty categories in dp. Journal of Linguistics 32:57-78.

Marchese, Lynell. 1979. Atlas linguistique kru. Abidjan: ILA.

Marchese, Lynell. 1988. 16 noun classes and agreement systems in kru: a historical approach. Agreement in natural language: Approaches, theories, descriptions 323.

Merchant, Jason. 2001. The syntax of silence: Sluicing. Islands, and the Theory of .

Pullum, Geoffrey, and Arnold Zwicky. 1988. The syntax-phonology interface. In Linguistics: The Cambridge survey, ed. Newmeyer, 255-280. New York: The Cambridge University Press.

Pullum, Geoffrey K, and Arnold M Zwicky. 1986. Phonological resolution of syntactic feature conflict. Language 751-773.

Rose, Sharon, and Rachel Walker. 2004. A typology of consonant agreement as correspondence. Language $475-531$.

Svenonius, Peter. 2004. On the edge. In Peripheries, 259-287. Springer. 